\title{
Studies on the development of Theileria annulata
}

\author{
Dschunskowsky and Luhs, 1904 \\ in the tick - Hyalomma anatolicum anatolicum \\ Koch, 1844
}

\author{
by Y. BHATTACHARYULU *, R. P. CHAUDHRI ** and B. S. GILL * \\ Indian Veterinary Research Institute \\ Izatnagar, U.P., INDIA
}

\section{Summary}

The endogenous development of Theileria annulata in the vector tick - Hyalomma anatolicum anatolicum has been described. Parasites within and outside the erythrocytes were seen in the gut contents of larvae and nymphs immediately after their removal from the infected cattle but not after 24 hours. Two bodies resembling the intra-erythrocytic stage of the parasite, lying close to each other were seen near the gut epithelium of a larva on the 4th day of its dropping off the infected host. Neither multiplication nor union of the parasite resulting in zygote formation in the gut of the tick, was noticed.

Next stage of the parasite was seen in the salivary glands of nymphs and adults. The pre-infective stage characterized by indistinct chromatin dots (nuclei) surrounded with cytoplasm was seen in alveolar cells of the salivary glands of nymphs and adult ticks from the first to the third day of their feeding on the host. This stage progressed to the infective stage consisting of distinct chromatin particles (the infective particles) surrounded with cytoplasm in the salivary glands of nymphs and adult ticks after the second and first day, respectively of feeding on the host. The infective particles were also seen within ducts of the salivary glands.

\section{Present addresses :}

* Punjab Agricultural University, Ludhiana, Punjab, India.

* Assam University, Gauhati, Assam, India. 


\section{Résumé}

Etude du développement de Theileria annulata Dschunskowsky et Luhs, 1904 chez la tique Hyalomma anatolicum anatolicum Koch, 1844.

Le développement endogène de Theileria annulata chez le vecteur Hyalomma anatolicum anatolicum est décrit. Les parasites intra et extra-érythrocytaires ont été observés dans le contenu intestinal des larves et des nymphes prélevées sur le bétail infesté, mais non au-delà de $24 \mathrm{~h}$. Deux corpuscules, voisins l'un de l'autre et ressemblant au stade intra-érythrocytique, ont été vus près de l'épithélium intestinal de la larve 4 jours après s'être détachéa de l'hô:e infesté. Aucune multiplication ni union des parasites pour former un zygote dans l'intestin de la tique n'ont été observées.

Le stade suivant a été vu dans les glandes salivaires des nymphes et des adultes. Le stade pré-infestant, caractérisé par des ponctuations distinctes de chromatine (nuclei) entourées de cytoplasme, était visible dans les cellules alvéolaires des glandes salivaires des nymphes et des tiques adultes, du $1^{\text {er }}$ au $3^{\text {e }}$ jour de leur repas sur l'hôte. Ce stade évolue vers le stade infestant consistant en particules chromatiniennes distinctes, infestantes, entourées de cytoplasme, le $2^{\circ}$ jour du repas sur l'hôte dans les glandes salivaires des nymphes, le $1^{\text {er }}$ jour dans celles des tiques adultes. Les particules infestantes ont été vues également dans les conduits des glandes salivaires.

\section{Introduction}

Except for the solitary observation of Sergent et al., (1936) of the formation of zygote of Theileria dispar (= Theileria annulata) in the gut of Hyalomma mauritanicum $(=H . d$. detritum $)$ and sporogony in salivary glands of the succeeding stage of the tick, information on the development of this parasite in ticks, is lacking. The present authors studied the development of Th. annulata in $H$. anatolicum anatolicum. Their observations are described in this paper.

\section{Materials and Methods}

The vector.

A colony of $H$. a. anatolicum was raised in the laboratory. Batches of clean larvae were allowed to feed on calves infected with $T h$. annulata. At 24 hour intervals, a few larvae were collected from the day of attachment to the day of full engorgement and from moulting to nymphs. Besides, some fully engorged larvae were maintained in the insectory for moulting as nymphs. These larvae were prepared for serial section cutting (vide infra). Squash preparations of some of the larvae collected while feeding on the infected calf and of some in the process of moulting were also prepared. Some of the resultant nymphs when 3 - day - old were released on a clean calf. A few nymphs were collected from 24 hours of the attachment to full engorgement and fixed, and some crushed to make squash preparations. 
Similarly, nymphs while feeding on an infected calf and during moult to adult stage were also fixed, and some crushed to make squash preparations. When 7 - day old, some of these infective adult ticks were released on a clean calf. A few ticks were taken off the calf periodically and processed as above. Thus the material from larvae, nymphs and adult ticks fed on Th. annulata - infected calves was available for the study of endogenous stages of the parasite. Similar preparations from ticks fed on uninfected calves were prepared for control.

\section{Squash preparations.}

Fully engorged larvae, partially engorged nymphs, and adult ticks collected as described above, were brushed with a camel hair brush, and crushed beetween two glass slides. The coarse particles were removed and soft contents smeared on the slides. Fully engorged nymphs and adult ticks were ripped open with sharp iridectomy knife and contents smeared on slides.

\section{Dissection.}

Partially and fully engorged adult ticks were dissected to remove salivary glands. Molten paraffin wax was poured in a petri - dish to half its depth and allowed to solidify. Paraffin in the centre of the petri-dish was liquefied by applying a hot spatula, and the tick to be dissected embedded in moulten paraffin with its dorsal surface facing upwards. On solidification of paraffin, the tick was fixed firmly. An incision was made along the entire dorso-ventral border of the tick with a sharp iridectomy knife, dorsal body wall removed, salivary glands located, cut at roots, lifted and placed in the fixative.

$10 \%$ formalin, Bouin's fluid, $70 \%$ alcohol, acetone and Carnoy's fluid were tried as fixatives. Carnoy's fluid was found to give best results and was adopted routinely.

\section{Section cutting of ticks.}

Un-engorged and partially engorged larvae and nymphs and un-engorged adult ticks were fixed by dropping in a fixative. These were pricked with a sterile needle to facilitate penetration of the fixative. Fully engorged larvae and nymphs were incised at the posterior end, the legs and protruding mouth parts amputated, and dropped in the fixative.

Ticks were fixed in Carnoy's fluid for 1-2 hours. These were then transferred to a mixture of $85 \%$ éthyl alcohol to which phenol has been added at the rate of 8 drops to $100 \mathrm{ml}$. of alcohol. After 24 hours, the ticks were removed, dehydrated in absolute alcohol, treated with amyl acetate for 24 hours and transferred to a mixture of methyl benzoate with $1 \%$ celloidin for 1-2 days or longer. The specimens were then transferred to benzol and embedded in paraffin wax (Martin et al., 1964). Paraffin wax with ceresin C.P., melting point $60^{\circ} \mathrm{C}$ was used. 
Some ticks after fixation and dehydration were transferred to 5 and $10 \%$ celloidinether-alcohol mixture, respectively for abut 7-10 days in each solution. Later, these were treated with chloroform for 12-24 hours and then with benzol for 1/2-1 hour. Finally, these were embedded in paraffin wax.

Out of the techniques employed, the specimens treated with methyl benzoate with $1 \%$ celloidin with or without prior treatment with amyl acetate gave best results.

4-6 $\mu$ thick sections were cut. Mollifex (B.D.H.) was employed to facilitate serial section cutting of fully engorged nymphs and adults.

\section{Staining.}

Sections were treated with xylene, absolute alcohol, descending grades of alcohol and brought to running water. These were stained with Giemsa stain (Shortt and Cooper, 1948). Prior to staining with Giemsa, sections were kept in haematoxylin solution for 4 seconds, blued in ammonia water and washed with distilled water. This procedure improved the quality of staining (Martin et al., 1964).

\section{Results}

\section{Endogenous stages.}

\section{From larva - to - nymph.}

Theileria parasites were first detected within and outside the erythrocytes in gut contents of the larvae, on the 3rd day of the attachment (fig. 1). No stage of the parasite was identified in preparations of the fully engorged larvae dropped from the Th. annulata - infected animal until the nymphal stage emerged. Only in one case on the fourth day after the larva had dropped of the infected host, two organisms were observed lying in close apposition near the border of the gut epithelium (fig. 2). These stages resembled the usual intra-erythrocytic forms of the parasite.

Next definitely identifiable stage of the parasite was in the salivary glands of the nymphs when these started feeding on the host. On the first day of attachment, a few acini of salivary glands contained a large number of indistinct chromatin particles stained faint red with Giemsa stain embedded in pale blue matrix (fig. 3). This stage was comparable to the 'pre-infective' stage of Th. parva described by Martin et al., (1964). Besides, parasites consisting of a number of distinct chromatin particles surrounded with indistinct blue cytoplasm (fig. 4 and 5), comparable to the 'infective' stage of Th. parva (Martin et al., 1964) were observed in a few acini in preparations of the nymphs of the second and third day of feeding on the host.

\section{From nymph - to - adult.}

Clean nymphs on the first day of attachment to a Th. annulata - infected animal, engorged very little amount of blood. Sections and smears prepared from them were free of the parasite. On the second day the intra-erythrocytic forms lying within or outside the erythrocytes in the gut contents were seen (fig. 6). 


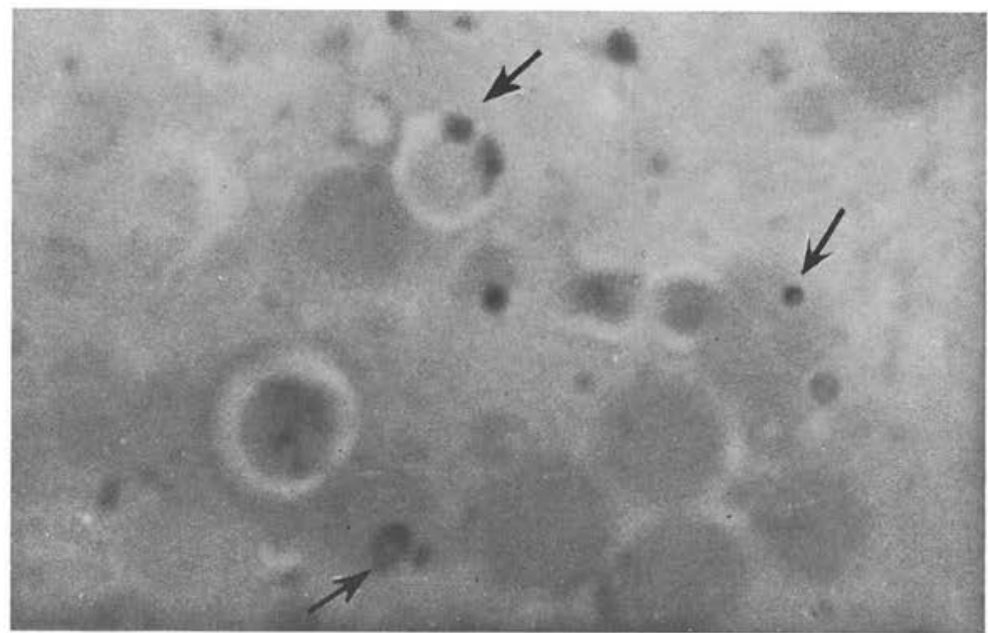

FIG. 1. - Photomicrograph of squash preparation of a larva fed for 3 days on a Theileria annulata - infected calf showing theileria parasites inside and outside the erythrocytes. $\times 1520$.

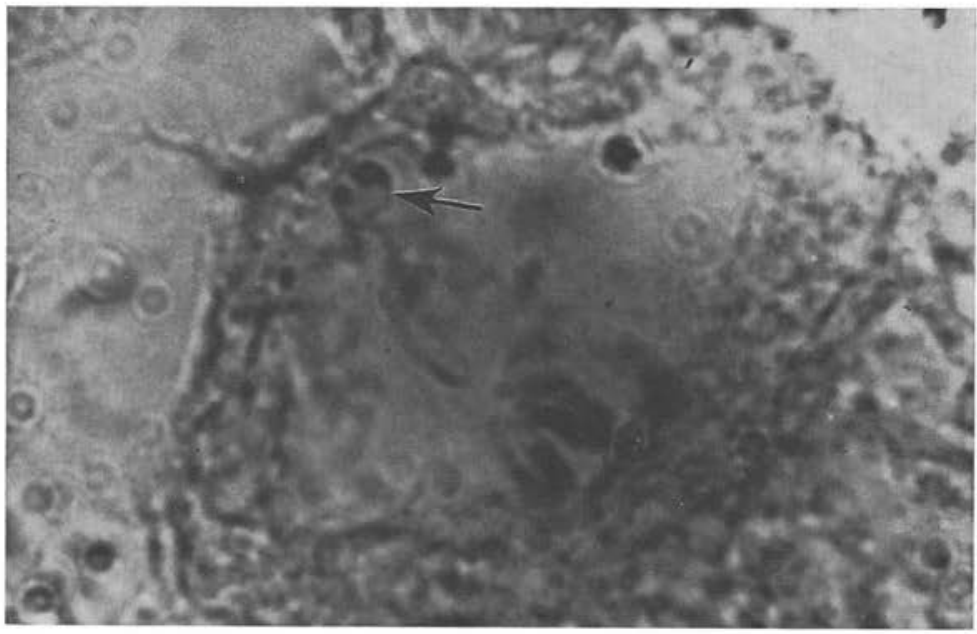

FIg. 2. - Photomicrograph of section of a larva 4 days after it dropped off a Theileria annulata - infected calf showing two parasites lying in close apposition near the border of gut epithelium. $\times 1350$.

No evidence of furher development of the parasite was present in preparations of the fourth day. In a preparation of the sixth day after dropping off the host, small chromatin bodies surrounded with faint blue cytoplasm were observed in the muscle fibre enclosing the gut wall of the nymphs (fig. 7). On the eighth day, cyst-like bodies 


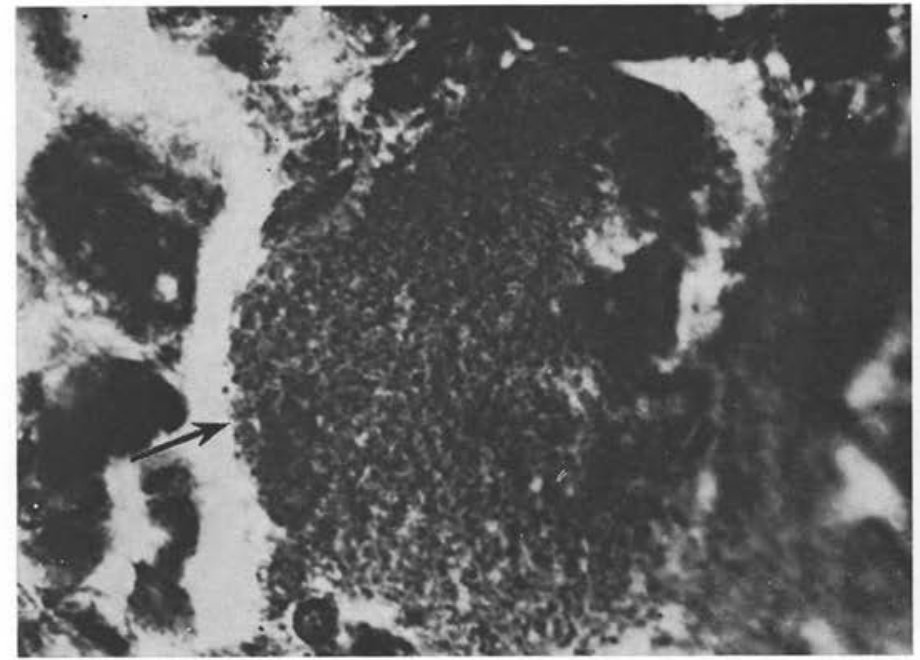

FIg. 3. - Photomicrograph of section of a 2 -day fed infective nymph showing the preinfective stage of Theileria annulata in the salivary gland. $\times 850$.

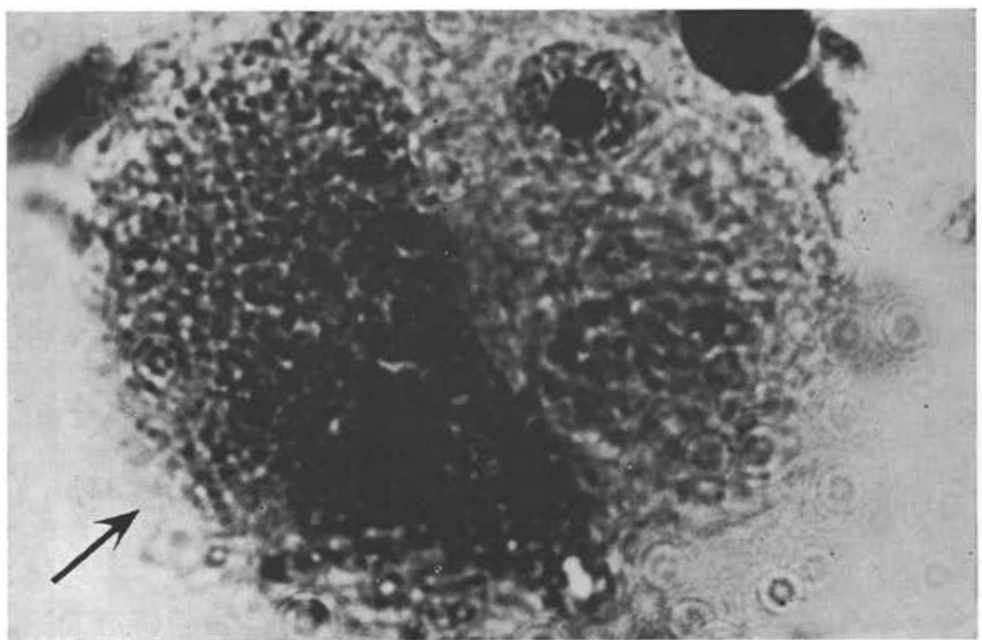

FIg. 4. - Photomicrograph of section of a 2 - day fed infective nymph showirg the infective stage of Theileria annulata in the salivary gland. $\times 1400$.

consisting of dark staining chromatin mass surrounded with light blue cytoplasm were seen in the gut epithélium of the nymphs (fig. 8). A number of parasites in the preinfective and infective stages, was observed in some acini of the salivary glands of the infective adult ticks from the first to third day of their attachment to the host. It was observed that the multiplication of the parasite in salivary glands of the infective 


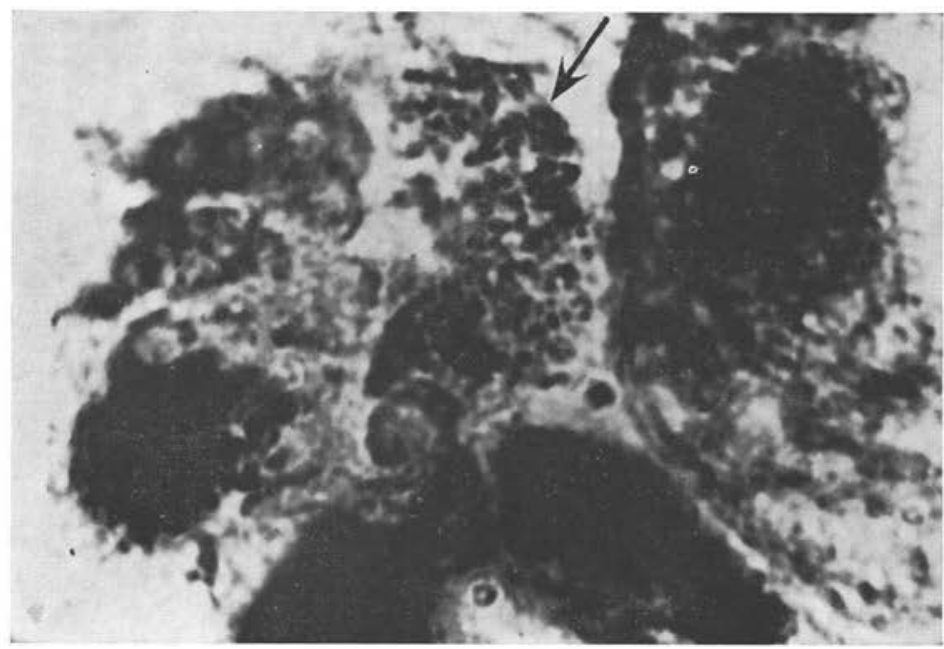

Fig. 5. - Photomicrograph of section of a 3 -day fed infective nymph showing a few infective particles of Theileria annulata in the salivary gland. $\times 1350$.

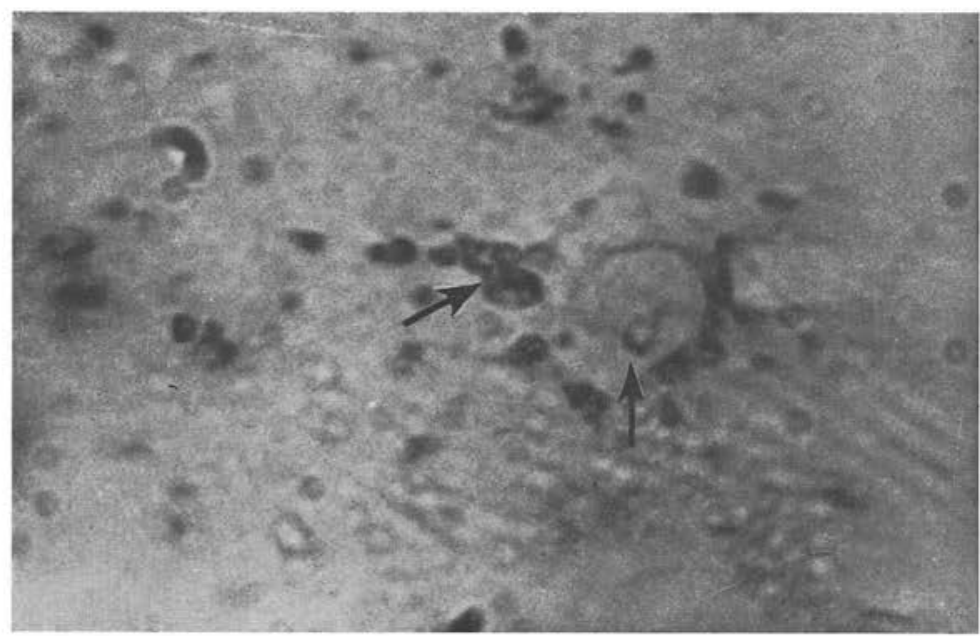

FIG. 6. - Pho:omicrograph of squash preparation of a nymph fed for 2 days on a Theileria annulata - infected calf showing the parasites within an erythrocyte and a group of three parasites outside host cell(s). $\times 1600$.

ticks was not correlated with the period of their attachment on the host as pre-infective (fig. 9), and infective (fig. 10) stages of the parasite were observed in different batches of ticks fed for the same period on the hosts.

Comparatively, more number of cells of salivary glands of the infective adult ticks was found to be parasitized than of the infected nymphs. In one case, a large Annales de Parasitologie humaine et comparée (Paris), t. 50, $\mathrm{n}^{\circ} 4$ 


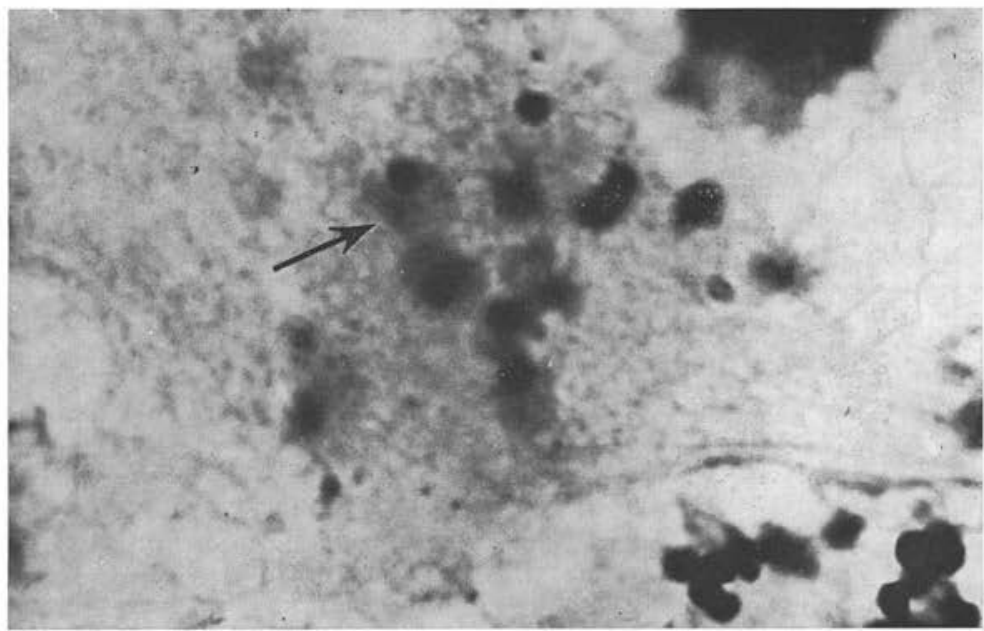

FIG. 7. - Photomicrograph of section of a nymph 6 days after it dropped off a Theileria annulata - infected calf, showing dark stained bodies with faint blue cytoplasm around them, in the gut musculature. $\times 1350$.

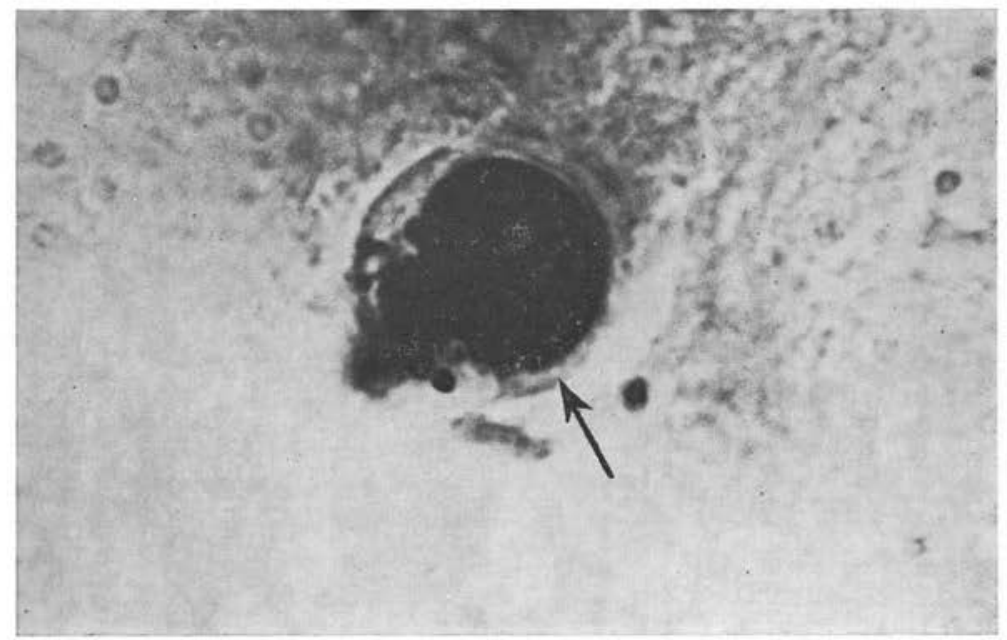

FIG. 8. - Photomicrograph of section of a nymph 8 days after it dropped off a Theileria annulata - infected calf showing a dark-stained cyst-like body in the gut epithelium. $\times 1500$.

number of infective particles of the parasite was noticed in the duct of the salivary glands of an infective adult tick (fig. 11). It appears that on completing development in alveolar cells of the salivary glands, the infective particles were drained into the salivary duct of the tick. Only the infective stage of the parasite was observed in salivary glands of the adult ticks on fourth day of their feeding on a calf (fig. 12). 


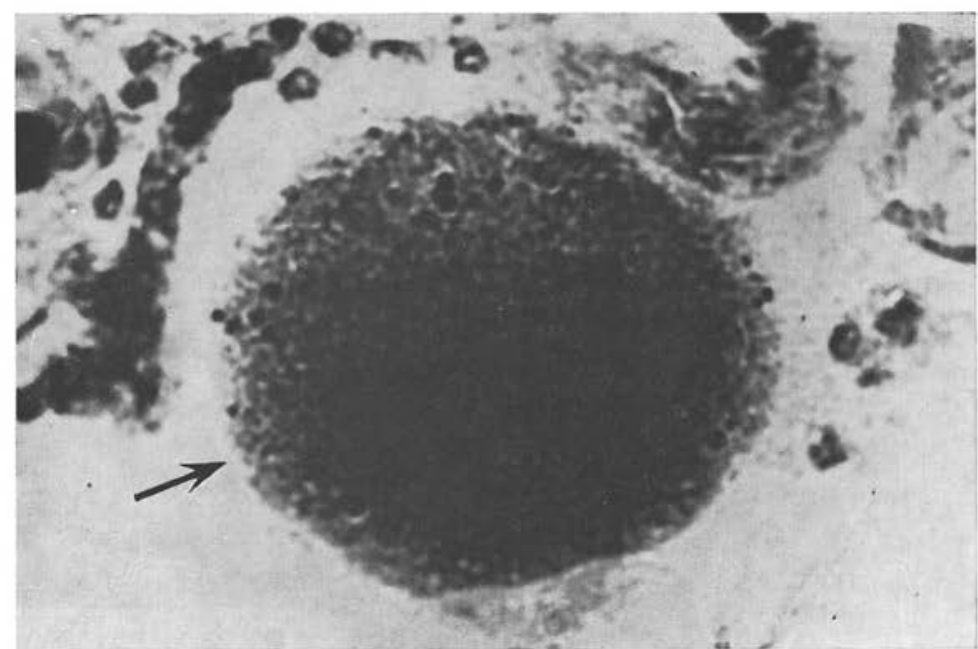

FIG. 9. - Photomicrograph of section of a 3-day fed infective adult tick showing preinfective stage of Theileria annulata in the salivary gland. $\times 800$.

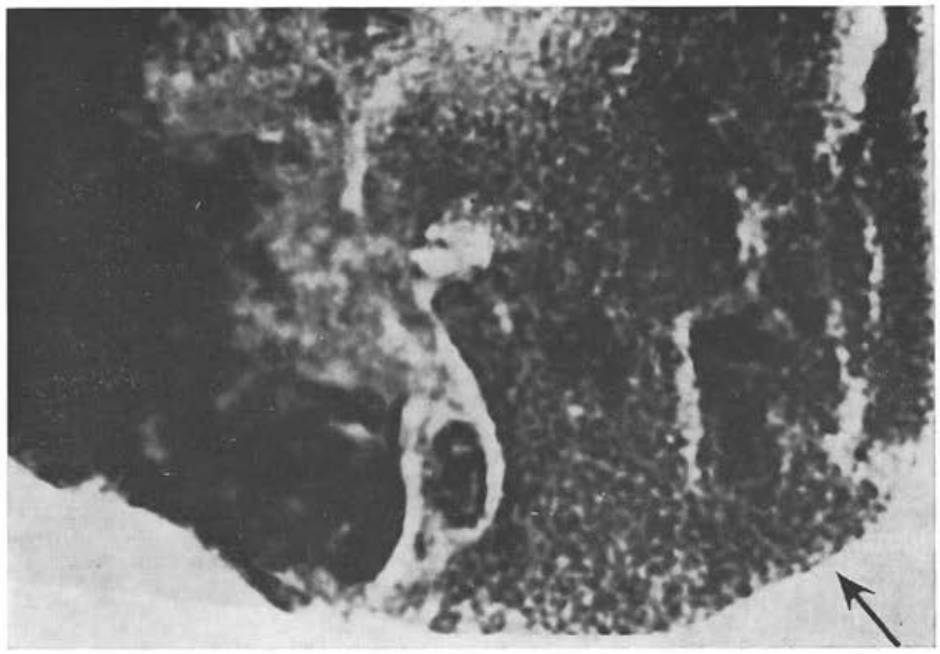

FIG. 10. - Photomicrograph of section of a 3 - day fed infective adult tick showing infective stage of Theileria annulata in the salivary gland. $\times 1200$. 


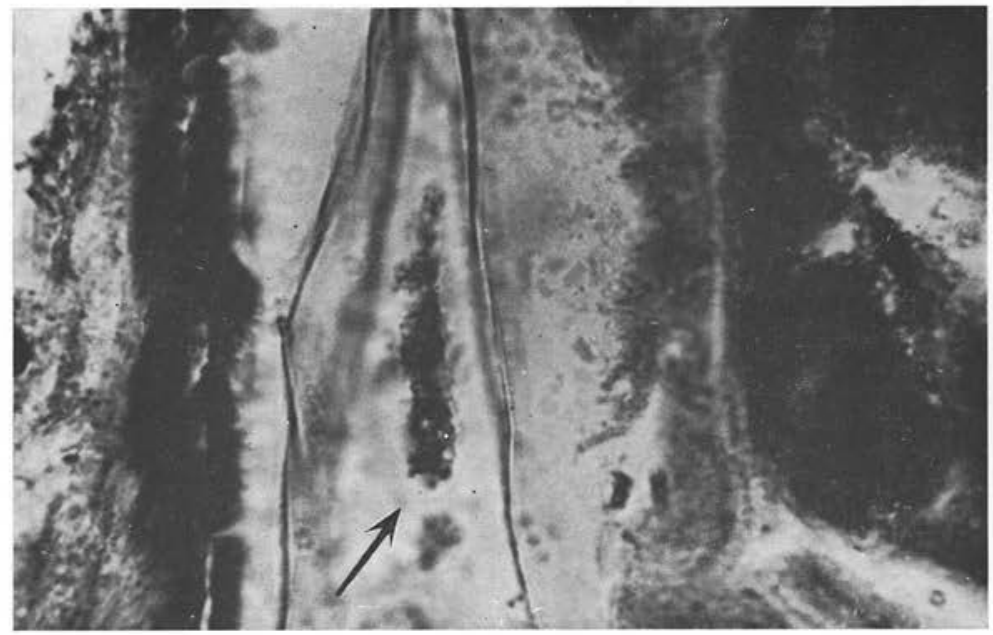

Fig. 11. - Photomicrograph of section of a 3 -day fed infective adult tick showing the infective stage of Theileria annulata in the salivary gland duct. $\times 850$.

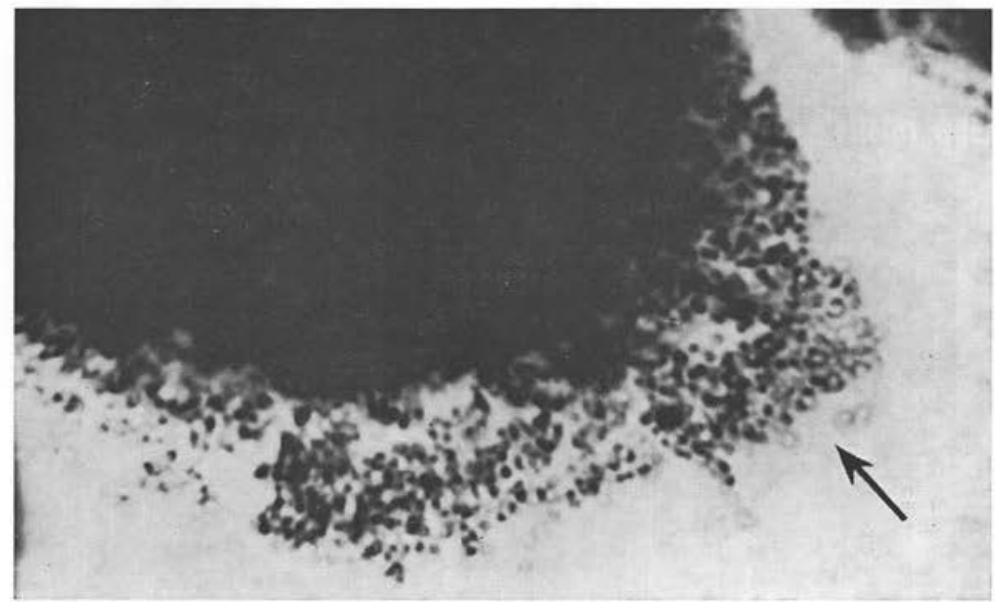

FIG. 12. - Photomicrograph of section of a 4 -day fed infective adult tick showing infective stage of Theileria annulata in the salivary gland. $\times 1350$. 


\section{Discussion}

In the present investigation, the intra-erythrocytic stage of Th. annulata lying in the gut of the larvae and nymphs of $H$. a. anatolicum was observed only immediately after their removal from the host (fig. 1). After that, erythrocytes were lysed so that parasites lying free in lumen of the gut of larvae were seen up to 24 hours and rarely for 4 days after dropping off the host (fig. 2). This finding agreed with the observations of Gonder (1911 a,b) and Martin et al., 1964) on Th. parva, and of Riek (1966) on Th. mutans. However, extended survival of 4-14 days, of the parasite in the gut lumen had been reported in case of Th. sergenti (Laptev, 1963) and Th. parva (Cowdry and Ham, 1932) which might have been due to low maintenance temperature of the ticks (Martin et al., 1964).

Sergent et al., (1936) described multiplication of Th. dispar ( $=T h$. annulata $)$ in gut and sporogony in salivary glands of $H$. mauritanicum. Similar observations were recorded by Gonder (1911 $a, b)$ and Cowdry and Ham (1932) on Th. parva in $R h$. appendiculatus. The present authors, however, did not find any evidence of multiplication of Th. annulata in the gut of $H$. a. anatolicum, which was in accord with those of Reichenow (1940) and Martin et al., (1964) on Th. parva in Rh. appendiculatus and of Riek (1966) on Th. mutans in H. bispinosa. The multiplication occurred only in salivary glands.

No stage of Th. annulata inside the gut tisue of the larvae and nymphs 4 and 2 days, respectively after they were dropped off the infected calves was seen. The nature of the dark staining structures observed in muscle fibres enclosing the gut wall of an infected nymph (fig. 7), and large cyst-like bodies detected in a few infected nymphs (fig. 8) was not clear. Riek (1966) observed spherical, elongate and multinucleate spherical bodies of uncertain nature in the gut of Th. mutans - infected larvae (H. bispinosa).

The present authors did not observe stage resembling zygote and are inclined to agree with Martin et al., (1964) who stated that the earlier workers (Sergent et al., 1936, Cowdry and Ham, 1932) misunderstood the degenerated tissue cells as theilerial zygote.

Next stage of the parasite seen was in the salivary glands of the ticks after these started feeding on a host as was also reported by Reichenow (1940), Martin et al., (1964) and Riek (1966). It appeared that blood meal stimulated the parasite in salivary glands to multiply. Cowdry and Ham (1932) and Reichenow (1940) stated that the parasite (Th. parva) reached salivary glands of the tick $R h$. appendiculatus, at the end of the reorganisation of the salivary glands before moulting of the nymph - to - adult stage. In the present study, the pre-infective stage was observed in a few acini of the salivary glands of nymphs (fig. 3) and adults (fig. 9) from the first to the third day of their feeding. The infective stage was seen in a few acini of the salivary glands of nymphs after the second day of feeding on the blood of the host (fig. 4 and 5) and in the adult (fig. 10 and 12) ticks after the first day of feeding on the host. 
The infective particles were constantly present in salivary glands of infective ticks and never in the non-infective ticks. This observation agreed with that of Riek (1966) who reported that the infective stage of $T h$. mutans in nymphs of $H$. bispinosa appeared two days after feeding on the host, and of Martin et al., (1964) that the infective stage of $T h$. parva appeared 24 hours after feeding of the adult tick ( $R h$. appendiculatus) on the host though Sergent et al., (1936) observed infective stage of Th. dispar (=Th. annulata) in salivary glands of $H$. mauritanicum earliest on the $3 \mathrm{rd}$ day of the feeding. However, other workers have recorded longer period ( 3 days - Cowdry and Ham, 1932 and $41 / 2$ days - Reichenow, 1949) of feeding on the host as necessary for the parasite (Th. parva) in salivary glands of the tick ( $R h$. appendiculatus) to reach infective stage.

Usually a small proportion of alveolar cells, whether of nymphs or adults, was found infected. Frequently, only a part of the salivary gland cell was infected. However, much variation in compactness and size of the parasites in salivary glands, was noticed. Similar observation was also reported by Martin et al., (1964) in salivary glands of $R h$. appendiculatus infected with $T h$. parva.

\section{Bibliography}

Cowdry (E. V.) and HAm (A.W.), 1932. - Studies on East-Coast Fever.I. The life cycle of the parasite (Theileria parva) in ticks (Rhipicephalus appendiculatus). Parasitology, 24, 1-49.

GoNDER (R.), 1911 a. - Die Entwicklung von Theileria parva, dem Erreger des Kustenfiebers der Rinder in Afrika. Arch. F. Protistenk., 21, 143-164.

GoNDER (R.), 1911 b. - Die Entwicklung von Theileria parva dem Erreger des Kustenfiebers der Rinder in Afrika. Arch. F. Protistenk., 22, 170-178.

LAPTEV (V.I.), 1963. - Development of Theileria sergenti in ticks. Trud. Vsesoyuz. Inst. Eks. Vet., 28, 124-128.

Martin (H. M.), BarnetT (S. F.) and Vidler (B. O.), 1964. - Cyclic development and longevity of Theileria parva in the tick Rhipicephalus appendiculatus. Exp. Parasit., 15, 527-555.

REICHENOW (E.), 1940. - Der Entwicklungsgang des Kustenfiebererreges im Rinde und in der übertragenden Zecke. Arch. F. Protistenk., 94, 1-56.

RIEK (R.F.), 1966. - The development of Babesia sp. and Theileria spp. with special reference to those occurring in cattle. In Biology of Parasites, éd. by E. J.L. Soulsby, Academic Press publ., London and New York, 354 p.

Sergent (Edm.), Donatien (A.), Parrot (L.) and Lestoquard (F.), 1936. - Cycle évolutif de Theileria dispar du Bœuf chez la Tique Hyalomma mauritanicum. Arch. Inst. Pasteur Alger., 14, 259-294.

ShortT (H. E.) and Cooper (W.), 1948. - Staining microscopical sections containing parasites by modification of McNamara's method. Trans. Roy. Soc. Trop. Med. Hyg., 41, 427-428. 